Original Research Article

\title{
Pharmaco-prophylaxis of deep vein thrombosis for in-patients at risk, in a tertiary care hospital
}

\author{
Sheetal John', Atiya R. Faruqui ${ }^{1 *}$, Soumya Umesh ${ }^{2}$
}

${ }^{1}$ Department of Pharmacology, ${ }^{2}$ Department of Medicine, St. John's Medical College Hospital, Bangalore, Karnataka, India

Received: 10 October 2017 Accepted: 24 November 2017

*Correspondence to:

Dr. Atiya R. Faruqui,

Email: atiyadoc@gmail.com

Copyright: (C) the author(s), publisher and licensee Medip Academy. This is an openaccess article distributed under the terms of the Creative Commons Attribution NonCommercial License, which permits unrestricted noncommercial use, distribution, and reproduction in any medium, provided the original work is properly cited.

\begin{abstract}
Background: There is limited data from India on Deep Vein Thrombosis (DVT) Prophylaxis. This study was done in hospitalised patients at high risk for DVT, to determine the patterns and rates of pharmacoprophylaxis, drugs used and their clinical outcomes.

Methods: This prospective study screened patients for risk of DVT using the Padua risk assessment model. Padua score $\geq 4$ were included and data on disease demographics, prophylaxis and outcomes of DVT at 12 weeks were collected. Factors affecting prophylaxis were assessed using multivariate logistic regression.

Results: Out of 453 screened, 200 eligible patients were recruited. $48.5 \%$ were females; mean age was $54.6 \pm 16.6 ; 50.5 \%$ received some thromboprophylaxis, of which $24 \%, 35.5 \%$ and $9 \%$ received pharmacoprophylaxis, mechanoprophylaxis and a combination of both respectively. Low Molecular Weight Heparin was the most commonly used drug (77.1\%). Adverse drug reactions reported were 24, none related to anticoagulant use. At 12 weeks, 18 (9\%) patients gave history suggestive of DVT. 5 deaths were reported, but the cause could not be ascertained. Patients who had cardiac/ respiratory failure $[\mathrm{OR}=5.2(95 \% \mathrm{CI}$ $1.13,24.6), \mathrm{p}=0.03]$, acute MI or stroke $[\mathrm{OR}=9.0(3.5,23.09), \mathrm{p}<0.001]$, those admitted to medical specialties $[\mathrm{OR}=3.4-1.4,7.9), \mathrm{p}=0.004]$ and to private wards $[\mathrm{OR}=7.4(3.13,17.5), \mathrm{p}<0.001]$ had significantly higher chances of receiving prophylaxis.

Conclusions: Underutilisation of effective prophylaxis, despite high prevalence of DVT risk. Emphasis on routine risk assessment of hospitalized patients and administration of appropriate prophylaxis to those at high risk is required.
\end{abstract}

Keywords: Deep vein thrombosis, Padua score, Prophylaxis, Venous thromboembolism

\section{INTRODUCTION}

Individuals with venous thrombosis constitute $0.64 \%$ of all hospital admissions, and two-thirds have Deep Vein Thrombosis (DVT) as their primary manifestation, while the remaining one-third has Pulmonary Embolism (PE). ${ }^{1,2}$

Among surgical patients, prevalence of DVT ranges from $15-40 \%$ among patients undergoing major general surgical procedures. $^{3}$ In Asian patients, incidence of DVT varies from $1.3 \%$ in spinal surgery to $41.7 \%$ following colorectal surgery. A systematic review and meta-analysis in Asian patients included 22 studies (total population 2454) published from 1979 to 2009 and suggested a possible trend toward increasing incidence of proximal DVT. ${ }^{4}$ Among those hospitalized for medical causes, 50\% - 75\% of VTE events, including fatal PE, occurred among hospitalized patients, as reported by a population based case control study. ${ }^{5}$

To help stratify the risk for VTE in hospitalized patients, several risk assessment models (RAMs) are employed. ${ }^{6}$ 
The Padua RAM was developed by the integration of the Kucher model in 2010, which includes 11 risk factors and has been shown to improve stratification of the thromboembolic risk in hospitalized patients. ${ }^{7}$ The risk of VTE was defined as low risk (total scores <4) and high risk (total scores $\geq 4$ ). This model has been used in the present study.

Clinical diagnosis of DVT is challenging due to its ambiguous clinical presentation. Venography is the gold standard for diagnosis; however it is an invasive procedure. . $^{8-10}$

Complications of DVT are severe pulmonary embolism, which develops in about one in 10 people with an untreated DVT. PTE is associated with mortality ranging from 30$75 \%$. The chances of re-thrombosis are up to $33 \%$ within 10 years of developing DVT. Post thrombotic syndrome (PTS) is the most common complication of DVT (50\%). It not only reduces the quality of life but is also responsible for considerable healthcare costs. ${ }^{11}$

Pharmacoeconomic studies have reported that treatment of an acute VTE is associated with an average incremental direct medical cost of Rs. 8,00,950 to Rs. 10,01,182 $(\$ 12,000$ to $\$ 15,000)$ among first year survivors, controlling for risk factors. Subsequent complications are conservatively estimated to increase cumulative costs to Rs. $12,01,428$ to Rs. $15,35,145$ ( $\$ 18,000$ to $\$ 23,000$ ) per incident case. $^{12}$

\section{Need for the study}

Literature shows high prevalence of patients at risk of developing DVT; despite the fact that prophylaxis prevents DVT, it is being underutilized. Though Western data are available, data from India, on DVT and its pharmacoprophylaxis, is limited. Hence, we conducted this study to determine patterns and rates of pharmacoprophylaxis, types of drugs used and their adverse reactions, in hospitalized patients, at high risk for development of DVT. This would help us in ascertaining the current practices pertaining to patient care and the findings may be useful to improve clinical practice.

\section{METHODS}

This study was conducted in a 1350 bedded tertiary care hospital in south India, having patient input from different geographic regions with fair representation of urban and rural population as well as varied socioeconomic strata.

\section{Study design and duration}

This was a prospective observational study with follow up at 12 weeks. Data were collected for 10 months from April 2015 to January 2016. Follow up was done at 12 weeks after recruitment, by telephone call, medical record review or both.

\section{Eligibility criteria}

Consenting patients aged 18 years and above, of both gender, who had a Padua risk prediction score of 4 or more and would also be able to provide 12 weeks follow up data were included.

Patients already on anticoagulants (for atrial fibrillation, post mitral valve replacement surgery etc.), those with other diagnosed hemorrhagic disorders (e.g. thrombophilias) and those in intensive care units and psychiatric wards at the time of recruitment, were excluded.

\section{Methods of data collection}

Permission was obtained from hospital administration office and a purposive sampling of patients were done from all eligible medical and surgical wards across the hospital. Written informed consent was taken from eligible patients and data were documented on a structured case record form (which was validated by circulation among experts, and suitable modifications made).

At recruitment, demographic and disease characteristics as well as treatment details were captured. These were followed up till their discharge from the hospital. The details of duration of hospital stay, number of days bedridden, evidence of developing DVT/ treatment for DVT, if any, were collected at discharge. A follow up of these patients was done at 3 months by telephonic interview along with data retrieval from case files.

\section{Sample size calculation}

Average prevalence of patients at risk of developing DVT was reported as $53 \%$ from a large multinational crosssectional study conducted by Cohen et al $(68,183$ patients). ${ }^{13}$ This percentage was used to calculate the sample size for this study. Assuming an absolute precision of $5 \%$, with a $95 \%$ confidence interval, the sample size required was 383 patients. Accounting for a loss to follow up of $20 \%, 450$ patients were required. As a pilot study, we have collected data from 200 patients.

\section{Statistical analysis}

Author summarized baseline data of patients (such as age, gender) as mean \pm standard deviation or median \pm interquartile range for continuous variables (ex. age, total number of drugs etc.) and frequencies with percentage, for categorical variables (ex. current smoking or alcohol use). Continuous variables were initially assessed for normality using Kolmogorov-Smirnov test and Q-Q plots; then analysed using independent t-test, if the variable was parametric and Mann Whitney U-test, if non-parametric. Categorical variables (ex. Padua score, $\mathrm{BMI} \geq 30$ ) were assessed using Chi-squared test. To assess the factors affecting administration of pharmaco- 
prophylaxis, we used multivariate logistic regression analysis.

A $p$ value $<0.05$ was considered significant for all tests. Data management was done on Epi info and statistical analyses were done using commercially available software SPSS (Statistics Package for Social Sciences, version 20).

\section{RESULTS}

A total of 453 in-patients from various wards were screened for eligibility and 200 out of them were recruited in this study (Table 1).

Table 1: Proportion of patients recruited from various specialities.

\begin{tabular}{|llll|}
\hline Department & $\begin{array}{l}\text { No. }(\%) \\
\mathbf{n = 2 0 0}\end{array}$ & $\begin{array}{l}\text { Department } \\
\text { Cardiology }\end{array}$ & $\begin{array}{l}\text { No. }(\%) \\
\mathbf{n}=\mathbf{2 0 0}\end{array}$ \\
\hline Dermatology & $6(3 \%)$ & $\begin{array}{l}\text { Cardiothoracic } \\
\text { surgery }\end{array}$ & 0 \\
\hline Endocrinology & $3(1.5 \%)$ & Gastrosurgery & 0 \\
\hline Gastroenterology & 0 & General surgery & $20(10 \%)$ \\
\hline $\begin{array}{l}\text { General } \\
\text { medicine }\end{array}$ & $28(14 \%)$ & Neurosurgery & $3(1.5 \%)$ \\
\hline Geriatrics & $3(1.5 \%)$ & OBG & $9(4.5 \%)$ \\
\hline Immunology & $3(1.5 \%)$ & Ophthalmology & $3(1.5 \%)$ \\
\hline Neurology & $5(2.5 \%)$ & Orthopedics & $34(17 \%)$ \\
\hline Nephrology & $6(3 \%)$ & Plastic surgery & $3(1.5 \%)$ \\
\hline $\begin{array}{l}\text { Pain and } \\
\text { palliative }\end{array}$ & 0 & Urology & $9(4.5 \%)$ \\
\hline PMR & $15(7.5 \%)$ & Vascular surgery & $3(1.5 \%)$ \\
\hline Psychiatry & 0 & & $17(8.5 \%)$ \\
\hline $\begin{array}{l}\text { Pulmonary } \\
\text { medicine }\end{array}$ & $21(10.5 \%)$ & Oncology & \\
\hline
\end{tabular}

\section{Patient characteristics at baseline}

Of the 200 high risk patients, 97 (48.5\%) were females and mean age was $54.6 \pm 16.6$ (Table 2). As compared to surgical wards, patients who were admitted to medical wards were significantly older patients $(p=0.008)$ with higher BMI $(\mathrm{p}=0.001)$ and higher average number of drugs per person $(p=0.006)$. However, reduced mobility was significantly more $(\mathrm{p}=0.013)$ among surgical patients.

\section{Padua risk assessment score during hospitalization}

In-patients from medical and surgical wards were stratified based on DVT risk (Table 3). It was found that $44.9 \%$ of surgical patients had a score of 5 and $6.1 \%$ had a score of 9. Among those admitted to medical wards, almost $75 \%$ of patients had scores between 4 and 6 .

Thromboprophylaxis- overall, pharmacological and mechanical prophylaxis

Among the high-risk patients (padua score $\geq 4$ ) recruited in present study, $50.5 \%$ received some form of thromboprophylaxis. Of these, only $24 \%$ received pharmacoprophylaxis (Table 4), $35.5 \%$ received mechanoprophylaxis and $9 \%$ received a combination of both.

Medical patients received significantly higher rates of pharmacoprophylaxis [31 (64.6\%) versus 17 (35.4\%) surgical, $\mathrm{p}=0.03$ ] (Table 5) and of these, oncology patients received higher rates of prophylaxis (Figure 2). Orthopedic patients received lower rates of prophylaxis when compared to their non-orthopedic counterparts $(11.9 \%$ vs. $21.4 \%$ )

The drugs received were categorized into 3 groupspatients who received heparin, LMWH or OACs (Figure 3). LMWH was most commonly used [37 (77.1\%)]. One patient received concomitant single dose of fondaparinux injection. In addition to anticoagulants, 23 patients were on antiplatelet, 13 on aspirin alone and 10 on a combination of aspirin and clopidogrel.

Limb exercises and lower limb physiotherapy were the most common mechanoprophylaxis measures practiced, followed by early ambulation and application of crepe bandage.

\section{Adverse drug reactions}

A total of 24 adverse drug reactions were reported during this study (Table 6). None of these were related to anticoagulant use. Causality assessment of these ADRs was done using the WHO scale and were uploaded onto the online database, VigiFlow.

Table 2: Baseline characteristics of patients.

\begin{tabular}{|c|c|c|c|c|}
\hline Parameter [n (\%)] & Total $(n=200)$ & Surgical [n=98 $(49 \%)]$ & Medical [n =102 (51\%)] & p value \\
\hline Females ${ }^{\#}$ & $97(48.5 \%)$ & $43(44.3 \%)$ & $54(55.7 \%)$ & 0.2 \\
\hline Age $^{\wedge}$ & $54.6 \pm 16.6^{*}$ & $50.0 \pm 24.0$ & $59.0 \pm 24.5$ & 0.008 \\
\hline Current smoking $^{\#}$ & $28(14.0 \%)$ & $17(60.7 \%)$ & $11(39.3 \%)$ & 0.1 \\
\hline Current alcohol use ${ }^{\#}$ & $19(9.5 \%)$ & $11(57.9 \%)$ & $8(42.1 \%)$ & 0.4 \\
\hline $\mathrm{BMI} \geq 30^{\#}$ & $45(22.5 \%)$ & $13(28.9 \%)$ & $32(71.1 \%)$ & 0.007 \\
\hline Reduced mobility (no: of days) ${ }^{\wedge}$ & $6.0 \pm 3.0$ & $7.0 \pm 5.0$ & $6.0 \pm 2.0$ & 0.013 \\
\hline Total no: of drugs per patient ${ }^{\wedge}$ & $8.0 \pm 9.75$ & $6.5 \pm 6.0$ & $8.0 \pm 10.0$ & 0.006 \\
\hline
\end{tabular}

\# Describe das number (\%); * Mean $\pm \mathrm{SD} ;{ }^{\wedge}$ Median (Interquartile range) 
Table 3: Padua risk assessment score during hospitalization.

\begin{tabular}{|lll|}
\hline $\begin{array}{l}\text { Padua } \\
\text { score }\end{array}$ & $\begin{array}{l}\text { Surgical }[\mathbf{n = 9 8} \\
(\mathbf{4 9 \%})]\end{array}$ & $\begin{array}{l}\text { Medical }[\mathbf{n = 1 0 2} \\
(\mathbf{5 1 \%})]\end{array}$ \\
\hline 4 & $6(6.1 \%)$ & $21(20.6 \%)$ \\
\hline 5 & $44(44.9 \%)$ & $31(30.4 \%)$ \\
\hline 6 & $32(32.7 \%)$ & $23(22.5 \%)$ \\
\hline 7 & $10(10.2 \%)$ & $13(12.7 \%)$ \\
\hline 8 & - & $14(13.7 \%)$ \\
\hline 9 & $6(6.1 \%)$ & - \\
\hline
\end{tabular}

Table 4: Thromboprophylaxis overall, pharmacological and mechanical prophylaxis.

\begin{tabular}{|c|c|c|}
\hline Parameter & $\begin{array}{l}\text { Pharmaco- } \\
\text { prophylaxis not } \\
\text { given } \\
\text { total }=152(76 \%)\end{array}$ & $\begin{array}{l}\text { Pharmaco- } \\
\text { prophylaxis } \\
\text { given total } \\
=48(24 \%)\end{array}$ \\
\hline $\begin{array}{l}\text { Mechanoprophylaxis } \\
\text { not given total = } 129 \\
(64.5 \%)\end{array}$ & $99(49.5 \%)$ & $30(15 \%)$ \\
\hline $\begin{array}{l}\text { Mechanoprophylaxis } \\
\text { Given total = } 71 \\
(35.5 \%)\end{array}$ & $53(26.5 \%)$ & $18(9 \%)$ \\
\hline
\end{tabular}

Table 5: Rates of pharmacoprophylaxis for DVT.

\begin{tabular}{|c|c|c|c|c|}
\hline $\begin{array}{l}\text { Parameter [n } \\
(\%)]\end{array}$ & Total & Surgical & Medical & $\begin{array}{l}\text { p } \\
\text { value }\end{array}$ \\
\hline $\begin{array}{l}\text { DVT } \\
\text { pharmaco- } \\
\text { prophylaxis } \\
\text { given }\end{array}$ & $\begin{array}{l}48 \\
(24.0 \%)\end{array}$ & $\begin{array}{l}17 \\
(35.4 \%)\end{array}$ & $\begin{array}{l}31 \\
(64.6 \%)\end{array}$ & 0.03 \\
\hline
\end{tabular}

\section{Comparison of patients who received with those who did} not receive pharmacoprophylaxis

Among the 48 (24\%) patients who received pharmacoprophylaxis (Table 7), 54.2\% were females, $41.7 \%$ were discharged from general wards and $2.8 \%$ had a $\mathrm{BMI} \geq 30$. As per Padua scoring, the most common reasons that predisposed patients to high risk of DVT (Table 9) were reduced mobility [194 (97\%)], acute infection/ rheumatologic disease [113 (56.5\%)] and recent trauma/ surgery $[100(50 \%)]$. Among patients who received pharmacoprophylaxis, $5(55.6 \%)$ had cardiac/ respiratory failure, $25(52.1 \%)$ had recent trauma or surgery and 17 (35.4\%) had acute MI or ischemic stroke.

Table 6: Adverse drug reactions reported.

\begin{tabular}{|llll|}
\hline ADRs (Total = 24) & Frequency & Suspected drugs & Causality assessment \\
\hline Constipation & 4 & Morphine, Tramadol & Probable \\
\hline Hypoglycemia & 4 & Insulin & Certain \\
\hline Hypokalaemia & 3 & Frusemide, dexamethasone & Probable \\
\hline Cushingoid features & 2 & Prednisolone & Possible \\
\hline Oropharyngeal candidiasis & 2 & Oral steroids & Probable \\
\hline Cataract & 1 & & Possible \\
\hline Normotensive glaucoma & 1 & Dexamethasone & Possible \\
\hline$\downarrow$ Bone mineral density & 1 & & Probable \\
\hline Diabetes & 1 & Steroids & Possible \\
\hline Drowsiness & 1 & Tramadol & Certain \\
\hline Pancytopenia & 1 & Azathioprine & Probable \\
\hline Epistaxis & 1 & Digoxin & Probable \\
\hline Impending hypoglycemia & 1 & Etoricoxib & Probable \\
\hline Encephalopathy & 1 & Sertraline & Possible \\
\hline
\end{tabular}

Table 7: Comparison of patients who received versus did not receive pharmacoprophylaxis.

\begin{tabular}{|c|c|c|c|c|}
\hline Parameter & $\begin{array}{l}\text { Total } \\
(\mathrm{n}=200)\end{array}$ & $\begin{array}{l}\text { Pharmaco-prophylaxis not } \\
\text { given }[\mathrm{n}=\mathbf{1 5 2}(\mathbf{7 6 \%})]\end{array}$ & $\begin{array}{l}\text { Pharmacoprophylaxis } \\
\text { given }[n=48(24 \%)]\end{array}$ & p value \\
\hline Females & $97(48.5 \%)$ & $71(46.7 \%)$ & $26(54.2 \%)$ & 0.3 \\
\hline \multicolumn{4}{|c|}{ Ward discharged from: } & \multirow{4}{*}{$<0.001$} \\
\hline General & $131(65.5 \%)$ & $111(73 \%)$ & $20(41.7 \%)$ & \\
\hline Private & $68(34 \%)$ & $40(26.3 \%)$ & $28(34 \%)$ & \\
\hline ITU & $1(0.5 \%)$ & $1(0.7 \%)$ & 0 & \\
\hline Current smoking & $28(14.0 \%)$ & $26(17.1 \%)$ & $2(4.2 \%)$ & 0.02 \\
\hline Current alcohol use & $19(9.5 \%)$ & $19(12.5 \%)$ & 0 & 0.008 \\
\hline $\mathrm{BMI} \geq 30 \mathrm{~kg} / \mathrm{m} 2$ & $45(22.5 \%)$ & $35(23.03 \%)$ & $10(2.8 \%)$ & 0.005 \\
\hline
\end{tabular}


Table 8: Evidence of DVT among patients who received versus did not receive pharmacoprophylaxis.

\begin{tabular}{|lllll|}
\hline Parameter [n (\%)] & $\begin{array}{l}\text { Total } \\
(\mathbf{n = 2 0 0})\end{array}$ & $\begin{array}{l}\text { Pharmaco-prophylaxis } \\
\text { not given }[\mathbf{n = 1 5 2}(\mathbf{7 6 \%})]\end{array}$ & $\begin{array}{l}\text { Pharmaco-prophylaxis } \\
\text { Given [n= 48 (24\%)] }\end{array}$ & p value \\
\hline E/o DVT: & $18(9 \%)$ & $1(0.7 \%)$ & 0 & 1.0 \\
\hline At discharge & $1(0.5 \%)$ & 10.16 \\
\hline On follow up & $17(8.5 \%)$ & $10(6.6 \%)$ & $7(14.6 \%)$ & 0.16 \\
\hline
\end{tabular}

Table 9: Comparison of risk profile for DVT among patients who received versus did not receive pharmacoprophylaxis.

\begin{tabular}{|lllll|}
\hline Parameter [n (\%)] & $\begin{array}{l}\text { Total } \\
(\mathbf{n = 2 0 0 )}\end{array}$ & $\begin{array}{l}\text { Pharmaco-prophylaxis } \\
\text { not given [n=152 (76\%)] }\end{array}$ & $\begin{array}{l}\text { Pharmaco-prophylaxis } \\
\text { given [n= 48 (24\%)] }\end{array}$ & p value \\
\hline \multicolumn{2}{|l|}{ Risk factors (as per padua risk prediction score): } & & $6(12.5 \%)$ & 0.8 \\
\hline Active CA & $23(11.5 \%)$ & $17(11.2 \%)$ & 0 & - \\
\hline Previous VTE & 0 & 0 & $48(24.7 \%)$ & 0.34 \\
\hline Reduced mobility & $194(97.0 \%)$ & $146(96.1 \%)$ & 0 & 1.0 \\
\hline Thrombophilia & $1(0.5 \%)$ & $1(0.7 \%)$ & $25(52.1 \%)$ & 0.74 \\
\hline Recent trauma/surgery & $100(50 \%)$ & $75(49.3 \%)$ & $7(14.6 \%)$ & 0.21 \\
\hline Elderly & $42(21 \%)$ & $35(23.0 \%)$ & $5(55.6 \%)$ & 0.04 \\
\hline Cardiac/ respiratory failure & $9(4.5 \%)$ & $4(44.4 \%)$ & $17(35.4 \%)$ & $<0.001$ \\
\hline Acute MI or ischemic stroke & $26(13.0 \%)$ & $9(5.9 \%)$ & $23(47.9 \%)$ & 0.17 \\
\hline $\begin{array}{l}\text { Acute infection or } \\
\text { rheumatologic disease }\end{array}$ & $113(56.5 \%)$ & $90(59.2 \%)$ & $10(20.8 \%)$ & 0.9 \\
\hline Obesity & $42(21.0 \%)$ & $32(21.1 \%)$ & $11(22.9 \%)$ & 0.17 \\
\hline Hormone therapy & $33(16.5 \%)$ & $22(14.5 \%)$ & & \\
\hline
\end{tabular}

Table 10: Predictors of thromboprophylaxis administration (univariate logistic regression).

\begin{tabular}{|lllll|}
\hline Parameter & OR & 95\% CI & Upper & p value \\
\hline Acute MI or ischemic stroke & 8.7 & Lower & 21.4 & $<0.001$ \\
\hline Discharged from PRIVATE ward & 2.3 & 1.5 & 3.7 & $<0.001$ \\
\hline Cardiac/ respiratory failure & 4.3 & 1.1 & 16.7 & 0.04 \\
\hline Elderly age & 1.0 & 1.0 & 1.0 & 0.03 \\
\hline Admitted to medical wards & 2.1 & 1.1 & 4.0 & 0.03 \\
\hline Increasing Padua score & 1.3 & 1.0 & 1.7 & 0.03 \\
\hline Reduced mobility & 1.1 & 0.9 & 1.2 & 0.12 \\
\hline Female gender & 1.3 & 0.7 & 2.6 & 0.37 \\
\hline H/o recent trauma or surgery & 1.1 & 0.6 & 2.1 & 0.74 \\
\hline Obesity & 0.9 & 0.4 & 2.2 & 0.97 \\
\hline
\end{tabular}

\section{Patient outcomes}

The main outcome we looked for was development of DVT at discharge and at 3 months of follow up (Figure4). A total of $18(9 \%)$ patients gave history suggestive of DVT (Table 8), which included reporting of symptoms such as pain, redness and swelling of lower limbs.

There were 5 deaths overall, but the cause of death could not be ascertained as cardiovascular or noncardiovascular. These outcomes were not significantly different between patients who received versus those who did not receive thromboprophylaxis.

\section{Factors determining administration of thromboprophylaxis}

Univariate analysis (Table 10) showed factors such as acute MI/ ischemic stroke, discharge from private wards, cardiac/ respiratory failure, older age, admission to medical wards, higher Padua scores and reduced mobility to have an influence on determining administration of pharmacoprophylaxis. Factors having $p$ value $<0.2$ in the univariate analysis were introduced into a multivariate logistic regression model (Table 11), which showed that patients who had cardiac/ respiratory failure [OR $(95 \% \mathrm{CI})$ $=5.2(1.13,24.6), \mathrm{p}=0.03]$, acute $\mathrm{MI}$ or stroke $[\mathrm{OR}=9.0$ (3.5, 23.09), $\mathrm{p}<0.001]$, patients admitted to medical 
specialties $[\mathrm{OR}=3.4(1.4,7.9), \mathrm{p}=0.004]$ and to private wards $[\mathrm{OR}=7.4(3.13,17.5), \mathrm{p}<0.001]$ had significantly higher chances of receiving thromboprophylaxis.

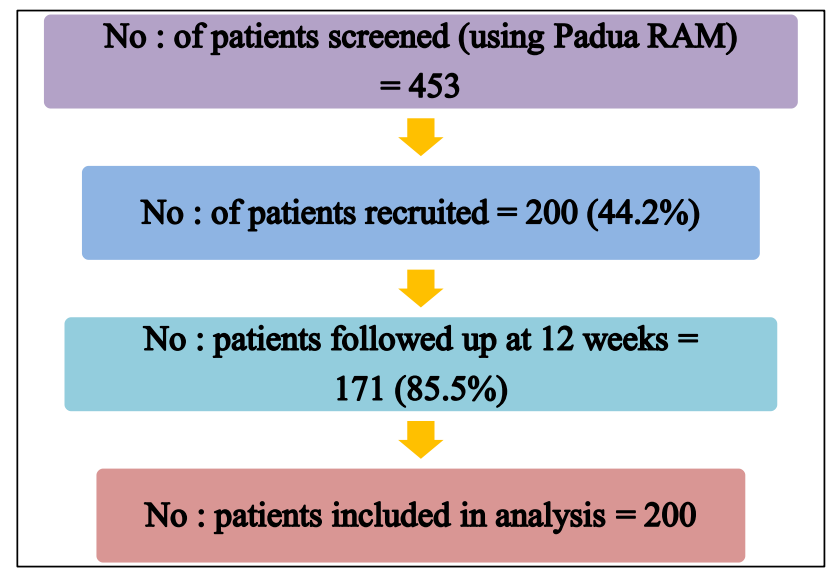

Figure 1: Study flow diagram.

Table 11: Predictors of thromboprophylaxis administration (multivariate logistic regression).

\begin{tabular}{|lclll|}
\hline Parameter & OR & $\begin{array}{l}\mathbf{9 5 \%} \text { CI } \\
\text { Lower }\end{array}$ & Upper & $\begin{array}{l}\mathbf{p} \\
\text { value }\end{array}$ \\
\hline $\begin{array}{l}\text { A/c MI or ischemic } \\
\text { stroke }\end{array}$ & 9.0 & 3.5 & 23.1 & $<0.001$ \\
\hline $\begin{array}{l}\text { Discharged from } \\
\text { private ward }\end{array}$ & 7.4 & 3.13 & 17.5 & $<0.001$ \\
\hline $\begin{array}{l}\text { Cardiac/ respiratory } \\
\text { failure }\end{array}$ & 5.2 & 1.13 & 24.6 & 0.03 \\
\hline $\begin{array}{l}\text { Admitted to medical } \\
\text { wards }\end{array}$ & 3.4 & 1.4 & 7.9 & 0.004 \\
\hline
\end{tabular}

\section{DISCUSSION}

We screened 453 hospitalised patients belonging to a spectrum of medical and surgical specialties using Padua RAM to assess their risk for development of DVT. The Padua Prediction score differentiates patients at high risk of VTE with a good discrimination. ${ }^{14} 44.15 \%$ of these patients had a Padua score $\geq 4$ indicating a high predicted risk for development of VTE. The rates of high-risk patients for VTE vary across the literature. The ENDORSE study(Evaluation of Patients at Risk for Venous Thromboembolism in the Acute Hospital Care Setting), a multi-national, cross-sectional survey, found $51.8 \%$ (with an inter-country range of $36-73 \%$ ) of subjects to be at a high risk for VTE. ${ }^{15}$ An analysis of the Indian subset of this study published by Pinjala and co-workers noted that the percentage of patients at risk was $53.16 \% .^{16}$ In contrast, lower rates of incidence $(39.7 \%)$ were reported by Barbar and co-workers in their landmark study of 1180 medical patients. ${ }^{14}$ Rosetto and co-workers also described a similar $(39.6 \%)$ incidence of patients at a higher risk for DVT. ${ }^{17}$ The high number of patients belonging to the high risk group signifies the importance of thromboprophylaxis and its possible positive impact on reducing the incidence of VTE by prophylactic measures.

\section{Medical-surgical comparison of incidence of patients at high-risk of DVT}

The number of medical patients at high risk of DVT was more $(51 \%$ vs. $49 \%)$ in our cohort. Thus, more than half the hospitalised patients in both surgical and medical wards seemed to be at a higher risk for VTE. In contrast, $64.4 \%$ (with an inter-country range of $44-80 \%$ ) surgical patients in the ENDORSE study were at a higher risk of development of VTE. The proportion of medical patients at high risk was lower at $41.5 \%$ (inter-country range of $21-71 \%) .{ }^{15}$ Pinjala and co-investigators noted that in Indian subset of patients, $44.7 \%$ of surgical patients and $61.3 \%$ of medical patients were at a higher risk of DVT and this was similar to present study. ${ }^{16}$ This difference of incidence would have possible impact on prescription practices and understanding reasons for non-utilisation of prophylactic measures.

\section{Differences between medical and surgical subgroups}

In medical patients at high risk of DVT, theparameters ofhigher age, higher BMI and more number of prescription drugs per patients in the Padua Risk Assessment Model, were noted, whereas surgical patients had a higher incidence of restricted mobility. Parameters like gender, type of ward admitted to (private/ common) and total Padua score were comparable between the medical and surgical groups.

\section{Prophylaxis in high-risk patients}

Thromboprophylaxis in a population at high risk of DVT has been found to reduce the incidence of DVT. The rate of VTE complications was found to be 30 times more in those patients who scored $\geq 4$ compared to those with $<4$. The use of mechanical compression systems (graduated compression stockings or intermittent pneumatic compression stockings) reduces the risk of DVT by onethirds when used alone; and by half when added to pharmacological method such as heparin or oral anticoagulant. ${ }^{18}$ In consideration of the high incidence of DVT and resultant high morbidity and mortality of associated pulmonary embolism and other sequelae, the identification and management of high risk patients is important. In our cohort, only $49.5 \%$ of patients who were at high risk for DVT received prophylaxis of any kind. $24 \%$ of them received only pharmacoprophylaxis, $35.5 \%$ only mechanopropylaxis and $9 \%$ a combination of both.

Previous studies have reported a range of DVT prophylaxis rates between 13-64\%. In ENDORSE, 50.2\% (with an inter-country range of 2-84\%) of high-risk patients received ACCP recommended prophylaxis and $17.4 \%$ in the Indian subset. ${ }^{15,16}$ 


\section{Difference in prophylaxis rates among medical and surgical populations at high risk for VTE}

ACCP recommended prophylaxis was given in $64.6 \%$ of eligible medical patients and $35.4 \%$ of eligible surgical patients in our cohort whereas Pinjala et al reported corresponding rates of $19.1 \%$ among medical patients and $16.3 \%$ among surgical. ${ }^{16}$ Thus the Indian literature describes higher adherence to ACCP guidelines among the medical patients. The findings of ENDORSE were in contrast to this, with reported higher rates of prophylaxis of $58.5 \%$ (inter-country range of $0.2-92 \%$ ) among surgical patients compared to $39.5 \%$ (inter-country range of 3$70 \%$ ) among medical patients. ${ }^{15}$ In a study of medical population by Rosetto and co-workers, $88.5 \%$ of high risk patients received anti-DVT prophylaxis. ${ }^{17}$ Otero and colleagues in a retrospective analysis of surgical patients from Spanish hospitals noted that the rate of appropriate prophylaxis was $64 \%$ (range from $27-70 \%$ ). ${ }^{19}$ In a study by $\mathrm{Yu}$ et al of hospital compliance of ACCP guidelines, a compliance rate of $13.3 \%$ (2.8\% for neurosurgery to $52.4 \%$ for orthopaedic surgery) was noted. ${ }^{20}$ The lesser compliance to ACCP guidelines in the surgical subpopulation in the Indian context is to be noted. This is probably related to the better awareness and use of risk assessment forms by physicians. The overall impact of this relative higher compliance on the outcome among the medical patients is unclear.

\section{Factors associated with receiving ACCP guided prophylaxis}

Patients were more likely to receive prophylaxis if they were admitted under medical departments, admitted to private wards or had cardiac/ respiratory failure, acute $\mathrm{MI} / \mathrm{stroke}$, as per present study findings. Obesity, female gender, reduced mobility or post-operative status or history of trauma was not found to affect the use of prophylaxis. An increasing Padua score was found to increase the odds for prescription of prophylaxis. The increased use of prophylaxis in patients with cardiac/respiratory failure/acute stroke/MI is in line with the evidence based practice of prescribing thromboprophylaxis in patients with poor cardiopulmonary reserve. The variation in prescription practices according to specialty of the attending physician has been noted by Amin and co-workers who noted higher rates among cardiologists, surgeons and physicians. They also found a difference based on the insurance status of the patients. ${ }^{21}$ It may be noted that the higher incidence in private wards may reflect such a trend.

\section{Drug related adverse effects}

The common reasons for underutilisation of drugs for prophylaxis are anxiety about drug related adverse events (such as bleeding complications), underuse of routine screening of hospitalised patients, lack of awareness regarding VTE clinical judgement of the treating physician regarding certain subsets of patients, cost concerns, lack of routine blood level monitoring etc.

Bleeding related complications were not reported in our cohort. Though a total of 24 drug reactions were reported, none was related to the use of anticoagulants used for pharmacoprophylaxis. Further, contraindications/ anxiety to use of pharmacoprophylaxis do not explain the underutilisation of mechanical prophylaxis (35.5\%).

Limitation of the present study has DVT occurrence at three months could not be assessed using gold standard (radiological) methods. Long term follow-up was not performed to evaluate the clinical effect of VTE prophylaxis. Reasons for non-compliance to ACCP guidelines could not be studied.

\section{Strengths}

Assessment of pharmacoprophylaxis was done at end of hospital stay by chart review, thus confirming that the full dose prophylactic regimen was continued over a period of hospital stay. This is in contrast to ENDORSE study which was a one-day, one-ward chart review without patient follow up during the course of stay in the facility. Author have reported differences between medical and surgical populations at high risk for VTE and identified the factors associated with use of pharmacoprophylaxis. This study reviews the drug related adverse events and their causal association to the use of pharmacoprophylaxis for VTE.

\section{CONCLUSION}

In conclusion, our results showed a high prevalence of DVT risk in hospitalized patients and underutilization of effective prophylaxis to a large extent. This confirms the need for increasing awareness about DVT risk, implementation of routine risk assessment for patients being hospitalized and administration of appropriate thromboprophylaxis for those at high risk. Additionally, a larger study powered to identify the outcomes in patients received versus not received adequate thromboprophylaxis, with objective assessment (radiological confirmation) of DVT occurrence, would bring to light the consequences of under-utilization of prophylaxis. This will help in successful management of DVT and prevent the morbidity and mortality due to VTE.

\section{ACKNOWLEDGEMENTS}

Authors would like to thank the patients who participated in this observational study, the hospital administration for granting us permissions and the hospital nursing staff.

Funding: No funding sources Conflict of interest: None declared

Ethical approval: The study was approved by the Institutional Ethics Committee 


\section{REFERENCES}

1. Spyropoulos AC, Lin J. Direct medical costs of venous thromboembolism and subsequent hospital readmission rates: an administrative claims analysis from 30 managed care organizations. J Manag Care Pharm JMCP. 2007;13(6):475-86.

2. Roshni S. General introduction and outline of the thesis. 2012. Available at: https://openaccess.leidenuniv.nl/bitstream/handle/188 7/18334/01.pdf.

3. Hirsh J, Hoak J. Management of deep vein thrombosis and pulmonary embolism. A statement for healthcare professionals. Council on Thrombosis (in consultation with the Council on Cardiovascular Radiology). Am Heart Ass. Circu. 1996;93(12):2212-45.

4. Kanchanabat B, Stapanavatr W, Meknavin S, Soorapanth C, Sumanasrethakul C, Kanchanasuttirak P. Systematic review and meta-analysis on the rate of postoperative venous thromboembolism in orthopaedic surgery in Asian patients without thromboprophylaxis. Br J Surg. 2011;98(10):1356-64.

5. Heit JA, Silverstein MD, Mohr DN, Petterson TM, O'Fallon WM, Melton LJ. Risk factors for deep vein thrombosis and pulmonary embolism: a populationbased case-control study. Arch Intern Med. 2000;160(6):809-15.

6. Huang W, Anderson FA, Spencer FA, Gallus A, Goldberg RJ. Risk-assessment models for predicting venous thromboembolism among hospitalized nonsurgical patients: a systematic review. J Thromb. 2013;35(1):67-80.

7. Barbar S, Noventa F, Rossetto V, Ferrari A, Brandolin $\mathrm{B}$, Perlati $\mathrm{M}$, et al. A risk assessment model for the identification of hospitalized medical patients at risk for venous thromboembolism: the Padua Prediction Score. J Thrombol Haemost JTH. 2010;8(11):2450-7.

8. Lensing AW, Prandoni P, Prins MH, Büller HR. Deepvein thrombosis. Lancet Lond Engl. 1999;353(9151):479-85.

9. Ten Cate-Hoek AJ, Prins MH. Management studies using a combination of D-dimer test result and clinical probability to rule out venous thromboembolism: a systematic review. J Thromb Haemost JTH. 2005;3(11):2465-70.

10. Wells PS, Owen C, Doucette S, Fergusson D, Tran H. Does this patient have deep vein thrombosis? JAMA. 2006;295(2):199-207.

11. Arina $\mathrm{CH}$. New developments in diagnosis and Treatment of deep vein thrombosis. Datawyse Maastricht; Available at: http://digitalarchive.maastrichtuniversity.nl/fedora/ge t/guid:87d5ea74-3702.../ASSET1. Accessed 20 Aug 2016.

12. Grosse SD, Nelson RE, Nyarko KA, Richardson LC, Raskob GE. The economic burden of incident venous thromboembolism in the United States: A review of estimated attributable healthcare costs. Thromb Res. 2016;137:3-10.

13. Cohen AT, Tapson VF, Bergmann J-F, Goldhaber SZ, Kakkar AK, Deslandes B, et al. Venous thromboembolism risk and prophylaxis in the acute hospital care setting (ENDORSE study): a multinational cross-sectional study. Lancet Lond Engl. 2008;371(9610):387-94.

14. Barbar S, Noventa F, Rossetto V, Ferrari A, Brandolin $\mathrm{B}$, Perlati $\mathrm{M}$, et al. A risk assessment model for the identification of hospitalized medical patients at risk for venous thromboembolism: the Padua Prediction Score. J Thromb Haemost JTH. 2010;8(11):2450-7.

15. Cohen AT, Tapson VF, Bergmann J-F, Goldhaber SZ, Kakkar AK, Deslandes B, et al. Venous thromboembolism risk and prophylaxis in the acute hospital care setting (ENDORSE study): a multinational cross-sectional study. Lancet Lond Engl. 2008;371(9610):387-94.

16. Pinjala R. Venous thromboembolism risk and prophylaxis in the acute hospital care setting (ENDORSE), a multinational cross-sectional study: Results from the Indian subset data. Indian J Med Res. 2012;136(1):60-7.

17. Rossetto V, Barbar S, Vedovetto V, Milan M, Prandoni P. Physicians' compliance with the Padua Prediction Score for preventing venous thromboembolism among hospitalized medical patients. J Thromb Haemost JTH. 2013;11(7):142830.

18. Roderick P, Ferris G, Wilson K, Halls H, Jackson D, Collins R, et al. Towards evidence-based guidelines for the prevention of venous thromboembolism: systematic reviews of mechanical methods, oral anticoagulation, dextran and regional anaesthesia as thromboprophylaxis. Health Technol Assess Winch Engl. 2005;9(49):1-78.

19. Otero R, Uresandi F, Cayuela A, Blanquer J, Cabezudo MA, De Gregorio MA, et al. Use of venous thromboembolism prophylaxis for surgical patients: a multicentre analysis of practice in Spain. Eur J Surg Acta Chir. 2001;167(3):163-7.

20. Yu HT, Dylan ML, Lin J, Dubois RW. Hospitals' compliance with prophylaxis guidelines for venous thromboembolism. Am J Health-Syst Pharm AJHP Off J Am Soc Health-Syst Pharm. 2007;64(1):69-76.

21. Amin A, Stemkowski S, Lin J, Yang G. Thromboprophylaxis rates in US medical centers: success or failure? J Thromb Haemost JTH. 2007;5(8):1610-6.

Cite this article as: John S, Faruqui AR, Umesh S. Pharmaco-prophylaxis of deep vein thrombosis for in-patients at risk, in a tertiary care hospital. Int J Basic Clin Pharmacol 2018;7:44-51. 